\title{
Role of Aberrant Glycosylation of IgA1 Molecules in the Pathogenesis of IgA Nephropathy
}

\author{
J. Mestecky ${ }^{a, b, g} \quad$ M. Tomana ${ }^{b} \quad$ Z. Moldoveanu ${ }^{a} \quad$ B.A. Julian ${ }^{a, b} \quad$ H. Suzuki ${ }^{a, f}$ \\ K. Matousovic ${ }^{a, g} \quad$ M.B. Renfrow ${ }^{c} \quad$ L. Novak ${ }^{d} \quad$ R.J. Wyatt ${ }^{\mathrm{e}} \quad$ J. Novak $^{\mathrm{a}}$ \\ Departments of a Microbiology, ${ }^{b}$ Medicine, ${ }^{c}$ Biochemistry/Molecular Genetics, and ${ }^{\mathrm{d}}$ Pathology, University of \\ Alabama at Birmingham, Birmingham, Ala., and ' University of Tennessee Health Science Center, Memphis, Tenn., USA; \\ f Juntendo University School of Medicine, Tokyo, Japan; ${ }^{9}$ Charles University, Schools of Medicine, Prague and \\ Pilsen, Czech Republic
}

\section{Key Words}

IgA nephropathy · Glycosylation • Immune complexes • Glycosyltransferases

\begin{abstract}
Studies of the properties of immune complexes (IC) in the circulation, urine, and mesangium of IgA nephropathy (IgAN) patients have provided data relevant to the pathogenesis of this disease. IC contain predominantly polymeric IgA1 molecules which are deficient in galactose $(\mathrm{Gal})$ residues on $\mathrm{O}$ linked glycan chains in the hinge region (HR) of their heavy $(\mathrm{H})$ chains. As a result of this aberrancy, a novel antigenic determinant(s) involving $\mathrm{N}$-acetylgalactosamine (GalNAc) and perhaps sialic acid (SA) of $O$-linked glycans is generated and recognized by naturally occurring GalNAc-specific antibodies. Thus, IC in IgAN consist of Gal-deficient IgA1 molecules as an antigen, and GalNAc-specific lgG and/or IgA1 as an antibody. IgG antibodies to Gal-deficient lgA1 are probably induced by cross-reactive microbial antigens; they are present at variable levels not only in humans with or without IgAN but also in many phylogenetically diverse vertebrate species. Incubation of human mesangial cells with IC from sera of IgAN patients indicated that stimulation of cellular proliferative activity was restricted to the large $(>800 \mathrm{kDa})$ complexes. These findings suggest that experimental ap-
\end{abstract}

proaches that prevent the formation of large Gal-deficient IgA1-IgG IC may be applied ultimately in an immunologically mediated therapy.

Copyright $\odot 2008$ S. Karger AG, Basel

\section{Introduction}

IgA nephropathy (IgAN), also called Berger disease after its discoverer, was described in 1968 [1] and is immunohistochemically characterized by the co-deposition of $\operatorname{Ig} \mathrm{A}$ and IgG in the glomerular mesangium. Although since 1968 hundreds of papers, several monographs, and proceedings from 11 International Symposia have been published, this most common form of primary glomerulonephritis continues to provide considerable challenge not only to nephrologists, but also to human geneticists, immunologists, biochemists, and pharmacologists [2-4].

The purpose of this paper is to summarize contributions of our laboratory to the understanding of the pathogenesis of IgAN. After almost two decades of studies on the structure and function of human secretory and serum $\operatorname{Ig} \mathrm{A}$, our laboratory became interested in IgAN in the mid1980s through stimulating interactions with local nephrologists, Drs. Galla and Julian, and this renal disease has remained one of the top priorities of our research. 


\section{Characterization of IgA1 Mesangial Deposits and Circulating Immune Complexes (CIC)}

In humans, IgA occurs in two subclasses biochemically distinct in their primary structures, particularly in the hinge region (HR) of heavy $(\mathrm{H})$ chains (see below). Furthermore, IgA1 and IgA2 differ in the content and composition of $\mathrm{H}$-chain-associated glycans, sensitivities to bacterial proteases, distribution in various body fluids, tissue localization of plasma cells, metabolism, and specificities to various types of antigens [5-7].

After the initial confusion with respect to the IgA subclass association, it is now firmly established that IgA1 and not IgA2 represents the exclusive IgA subclass in mesangial deposits $[8,9]$. Further immunohistochemical studies indicated that IgA1 is deposited in the polymeric (p) form, as determined by the staining for J chain exclusively found in pIgA or IgM [7], and with the currently unexplained dominance of light (L) chains of the $\lambda$ isotype [10]. Complement component C3 and IgG and IgM represent the most frequent co-deposits [9]. These findings suggested that the mesangial IgA1 deposits are composed of ICs; however, it was not clear whether such ICs are formed in situ or are derived from the circulation. Many studies, including those from our laboratory [1113], convincingly documented the parallelism in composition of CIC and mesangial deposits: IgA1 as the exclusive IgA subclass, C3, and IgG or, at low levels, IgM; in comparison, IgA2-containing CIC were detectable only at low levels in a very few patients $[9,11]$. Determinations of molecular masses of CIC by sucrose gradient ultracentrifugation revealed a considerable degree of heterogeneity with sedimentation constants ranging from 11 to $19 \mathrm{~S}$ [11]. This finding proved to be an important point with respect to the restricted nephritogenicity of CIC, as determined by cultures of human mesangial cells with CIC of different molecular masses (see below). Upon dissociation of CIC at acid $\mathrm{pH}$, both $\mathrm{p}$ and monomeric (m) forms of IgA1 were detected $[11,13]$.

\section{Mesangial Deposits and CIC: Is the Antigen of Exogenous or Endogenous Origin?}

By definition, IC are composed of an antigen and corresponding antibody that may also bind complement components. The nature of antigen(s) in CIC and mesangial deposits of IgAN patients has remained an enigma since the discovery of this disease. The possible involvement of exogenous antigens stems from both clinical and experimental observations. The onset of macroscopic hematuria shortly after an upper respiratory or intestinal tract infection frequently heralds the clinical manifestations. Furthermore, extended feeding of mice with dietary proteins leads to their mesangial deposition, accompanied by IgA [14]. Collectively, these findings suggested that exogenous antigens of microbial or food origin may play an essential role, as components of CIC, in the pathogenesis of IgAN. Consequently, extensive studies of such antigens deposited in the mesangium commenced. A brief list of potential antigens that have been evaluated exemplifies their obvious heterogeneity. Positive staining in some studies, but not in others, was observed for antigens of herpes simplex virus 1 and 2, cytomegalovirus, Epstein-Barr virus (EBV), hepatitis B virus, adenovirus, soybean protein, casein, and bovine whey proteins [for review, see 15]. Therefore, these approaches did not convincingly identify a uniformly encountered exogenous antigen as a component of the mesangial deposits and/or CIC. Endogenous glomerular antigens such as basement membrane collagens have been considered as components of in situ-formed IC in IgAN [16]. However, other reports questioned their participation [17].

\section{Molecular Aberrancy of IgA1 Molecules in IgAN}

The possibility that IgAN is a disease associated with a molecular aberrancy and/or defect of IgA1 was suggested by a reduced reactivity of IgA in the sera of IgAN patients with jacalin, a lectin [18] specific for $O$-linked glycan side chains containing $\mathrm{N}$-acetylgalactosamine (GalNAc) and galactose (Gal) linked by $\beta 1,3$-glycosidic bond. However, this study did not provide information elucidating the molecular basis of this reduced reactivity.

Shortly after Andre et al. [18] observation that the serum IgA from patients with IgAN exhibited diminished binding to jacalin and our studies $[12,13,19]$, we proposed at the International Symposium on IgA Nephropathy in 1992 and published a year later that the Gal deficiency is restricted to $O$-linked glycan chains attached to the HR of IgA1. Furthermore, in 2001, two groups reported that IgA1 molecules in the mesangial immune deposits are aberrantly glycosylated [20,21]. This structural variation greatly influences the tissue distribution of such Gal-deficient molecules [22].

It may surprise many nephrologists as well as immunologists that humans daily produce more IgA than all other immunoglobulin isotypes combined [7, 23, 24]. Approximately two thirds of IgA are produced in mucosal 
Fig. 1. The HR of human IgA1 and IgA2 including the potential structures of $O$-linked glycan chains. Glycosyltransferases involved in the biosynthesis and glycosidases involved in the enzymatic removal of sugars are listed on the left and right, respectively. Reactivities of particular $O$-linked glycans of various structures with lectins specific for GalNAc- $\beta 1,3 \mathrm{Gal}$ (jacalin) and terminal GalNAc (HAA), ASGP-R expressed on hepatocytes and specific for terminal Gal or GalNAc are specified.

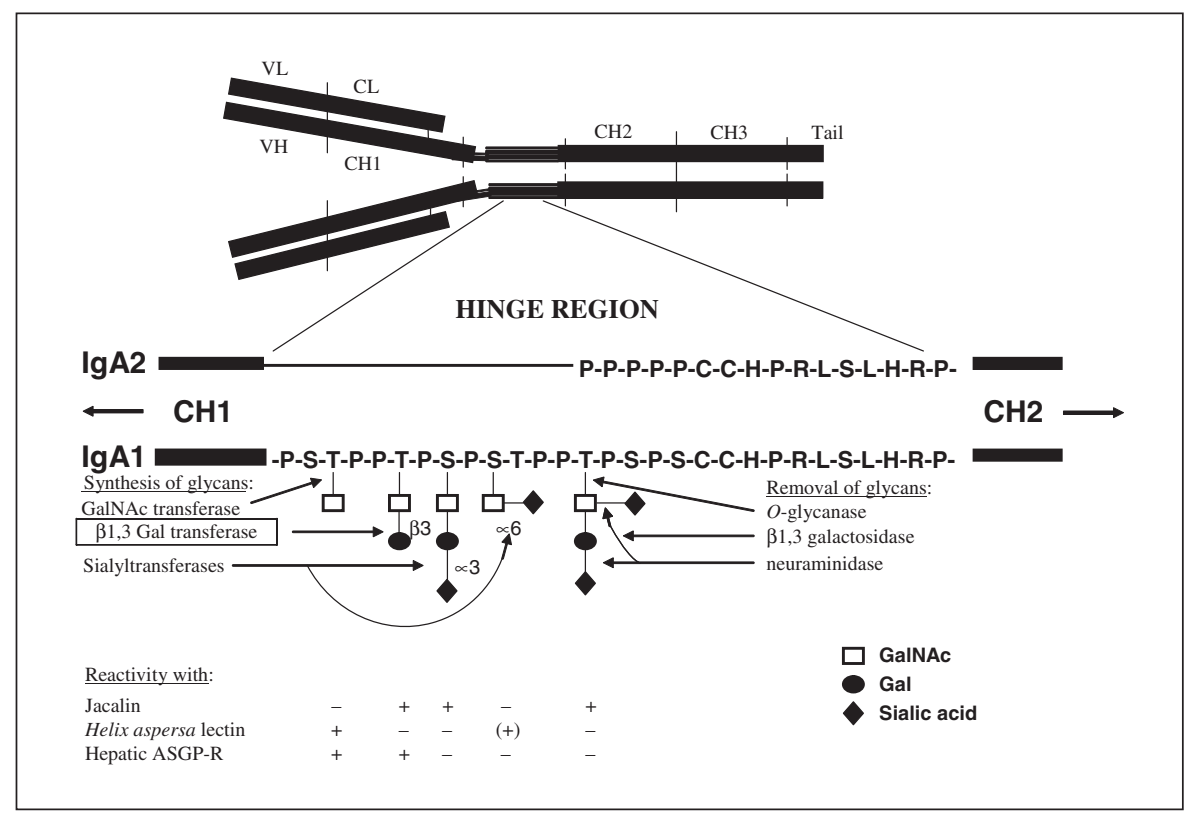

tissues, particularly in the intestinal tract, and are selectively transported into external secretions. Plasma IgA originates in the bone marrow and to a lesser extent in the spleen and lymph nodes. The lower plasma level of IgA than IgG is the result of its more rapid catabolism (the half-life of IgA is $\sim 5-6$ vs. $\sim 20-25$ days for $\operatorname{IgG}$ ). Experiments with both mice and primates clearly indicated that the liver is the major organ involved in the catabolism of IgA and other glycoproteins [25-28]. The asialoglycoprotein receptor (ASGP-R) expressed on hepatocytes interacts with terminal Gal or GalNAc on various glycoproteins, which are degraded after internalization $[25,28]$. We have demonstrated that IgA molecules of both subclasses are also bound, internalized, and catabolized by human hepatoma cell lines [28]. Therefore, the loss of terminal Gal on $O$-linked glycans should not profoundly influence these processes because interactions between ASGP-R and GalNAc of the IgA1 HR would not be impaired. This apparent contradiction was explained by detailed analyses of CIC $[12,13]$. Gal-deficient IgA was present exclusively in IC. It was bound to IgG with specificity to GalNAc as demonstrated by inhibition of the re-association of IC with GalNAc-containing compounds. Consequently, terminal GalNAc residues with the potential to interact with the ASGP-R are covered by specific antibodies that prevent such interactions $[12,13,29]$.

The most striking structural feature that differentiates human IgA1 from immunoglobulins of all other isotypes is its unique HR (fig. 1). Comparative evolutionary studies of IgA HR of many species [7, 30] clearly indicate that a relatively recent insertion of a gene segment encoding for an additional thirteen amino acids occurred into the phylogenetically older IgA2 gene. The origin of this insertion is unknown, although by its amino acid composition and sequence, and the presence of $O$-linked glycans, the human IgA1 HR remotely resembles mucin. However, other properties, such as susceptibility to proteolytic enzymes of bacterial origin [31], are distinct and absolutely unique. It should be stressed that only in humans and hominoid primates, such as chimpanzees and gorillas, IgA1 chains contain $\mathrm{HR}$ with minor differences in their primary structures. The structural or functional advantage (or disadvantage) conferred by the HR insertion into the hominoid primate $\mathrm{H}$ chains remains obscure.

Our studies of the antigenic determinants on human IgA1 that are recognized by naturally occurring antibodies revealed the dominant role of $O$-linked glycan moieties $[12,13]$. Thus, the enzymatic removal of $O$ linked glycans by endoglycosidases resulted in the reduction or loss of reactivity with antibodies, and the reformation of acid-dissociated IC was partially inhibited by Gal-deficient IgA1 or other glycoproteins bearing $O$ linked glycans with terminal GalNAc. However, the exact localization and relative involvement of individual $O$-linked glycan chains have not been precisely determined. Deficiency of Gal resulting in the exposure of GalNAc (either as the terminal glycan or perhaps its si- 


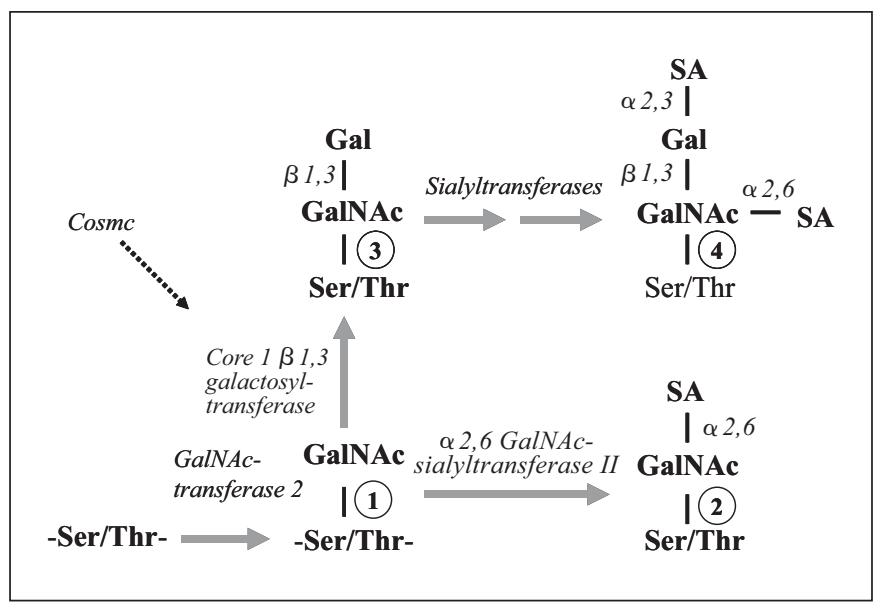

Fig. 2. Biosynthesis and variants of $O$-glycans in the $H R$ of human IgA1. Variant 1 reacts with GalNAc-specific lectins, such as HAA; variant 2 reacts with this lectin only after neuraminidase treatment to remove sialic acid (SA); and variants 3 and 4 do not react with HAA. Variants 1 and 2 on serum IgA1 are more common in patients with IgAN than in healthy controls $[12,13,37,70]$; variants 3 and 4 on the serum IgA1 are more common in healthy controls than in patients with IgAN [71].

alylated form) is essential for the reactivity with corresponding antibodies. In all of our studies, human myeloma IgA1 proteins have been used. Despite their monoclonal character, such proteins still display a marked heterogeneity in the number, sites of attachment, and composition of $O$-linked glycans [32-34]. Limited studies concerning the localization of antigenic determinants using Fab and $\mathrm{Fc}$ fragments generated by various bacterial proteases [31] suggest that Ser/Thr residues 228 and/ or 230 carry GalNAc residues that are recognized by anti-GalNAc antibodies [35, 36].

Another important point concerns the number of Galdeficient $O$-linked glycan chains. We detected Gal-deficient IgA1 in complexes with IgG in the high-molecularmass fractions of sera from IgAN patients by its reactivity with the GalNAc-specific lectin from Helix aspersa (HAA) [12, 13, 37]. Therefore, not all terminal GalNAc residues in the IgA1 HR are occupied by corresponding antibodies. It is reasonable to speculate that in addition to the terminal GalNAc, conformation and/or sequence of the polypeptide chain may differentially affect the exposure to anti-glycan antibodies and the reactivity with HAA. Obviously, additional experiments addressing these points must be performed.

Our recent studies of patients with IgAN showed that IgA1 secreted by peripheral blood lymphocytes and their
EBV-transformed cell lines was more likely to be Gal-deficient compared with the IgA1 obtained from similar cells of healthy controls [38].

\section{GalNAc-Specific Antibodies}

Although Gal-deficiency of IgA1 molecules in CIC and mesangial deposits in IgAN patients has been reported by several investigators [for reviews, see $2-4,39,40$ ] our previous contention that Gal-deficient IgA1 is an antigen recognized by GalNAc-specific naturally occurring antibodies has not been fully explored.

Anti-GalNAc antibodies of the IgG isotype are present in sera of all IgAN patients and healthy individuals, as well as in cord blood or intravenous gammaglobulin preparations [12, 13, 36, 38, 41-44]. Furthermore, cells secreting antibodies specific for Gal-deficient IgA1 can be easily detected and enumerated in peripheral blood from IgAN patients and, at lower frequency from normal individuals, by ELISPOT or immunofluorescence. Antibodies specific for Gal-deficient human IgA1, but not IgA2, are present in IgG from sera of many phylogenetically diverse vertebrate species, including pigs, rabbits, cows, donkeys, goats, sheep, mice, and rats [36]. The origin of these naturally occurring antibodies remains unclear. However, many microorganisms (both viruses and bacteria) express GalNAc-containing glycan side chains on their surface structures and are likely to induce antibodies that cross-react with analogous structures on IgA1 or other cell-associated glycoproteins.

\section{Molecular Basis of Gal Deficiency in the HR of IgA1}

$O$-linked glycans of IgA1 are synthesized in a stepwise manner, beginning with attachment of GalNAc to Ser or Thr, catalyzed by UDP- $N$-acetylgalactosaminyl-transferase 2 (GalNAcT2) [45] (fig. 2). The $O$-glycan chain is then extended by the attachment of Gal to GalNAc. The addition of $\mathrm{Gal}$ is mediated by core $1 \beta 1,3$-galactosyltransferase $(\mathrm{C} 1 \beta 3 \mathrm{GalT} 1)$ that transfers Gal from UDP-Gal to a GalNAc residue [46]. The stability of this enzyme depends on its interaction with a chaperone, Cosmc (C1ß3GalT1specific molecular chaperone) [46-49]. In the absence of Cosmc, the $\mathrm{C} 1 \beta 3 \mathrm{GalT} 1$ protein is degraded rapidly, thereby resulting in undergalactosylation of GalNAc in $O$ linked glycans. The glycan structure is completed by sialyltransferases (specific for $\alpha 2,3-\mathrm{Gal}$ and $\alpha 2,6-\mathrm{GalNAc}$ ) that attach negatively charged SA to the Gal or GalNAc 
residues. Sialylation of GalNAc in IgA1-secreting cells is mediated by a GalNAc-specific $\alpha 2,6$-sialyltransferase, ST6GalNAcII [50]. If SA is linked to GalNAc prior to attachment of Gal, this 'premature' sialylation precludes subsequent attachment of a Gal residue [40, 50, 51]. Thus, the relative activity of ST6GalNAcII and C1ß3GalT1/ Cosmc can directly influence the glycosylation of IgA1.

Our recent studies with EBV-immortalized cell lines from peripheral blood lymphocytes of patients with IgAN and healthy controls confirmed the above-described pathways in the IgA1-secreting cells [38]. Furthermore, detailed analysis of enzymatic activities in the cell lines from patients with IgAN indicated an imbalance in the activities of the pertinent glycosyltransferases. The C1ß3GalT1 activity was significantly lower and the GalNAc-specific $\alpha 2,6$-sialyltransferase activity was significantly higher. Studies of the aberrant glycosylation in IgAN represent a promising field with a potentially great impact on the future care of patients [52].

\section{Generation of IC and Their Functional Activities}

Because Gal-deficient IgA1 is predominant in highmolecular-mass fractions of serum whereas anti-GalNAc antibodies are easily detectable in their free form, it is obvious that CIC present in the patients' sera are formed in the antibody-excess zone. We stress that our studies focused on CIC that contain GalNAc-specific antibodies of the IgG isotype and therefore did not fully consider CIC containing other isotypes that probably differ in both physicochemical and biological properties. Nevertheless, biological effects of CIC in vivo are likely to depend on the portion of CIC that exhibit either stimulatory or inhibitory effects on cultured human mesangial cells [53]. This, in turn, might reflect the composition (including immunoglobulin isotype), charge, size, tissue and body fluid distribution, and reactivity with relevant cellular receptors. The latter point is of particular importance: terminal Gal or GalNAc on glycoprotein molecules of limited size is recognized and internalized by the hepatic ASGP-R. Although we proposed that anti-GalNAc antibodies inhibit the removal of Gal-deficient IgA1 in the liver, there are still free terminal GalNAc residues available, as evidenced by their HAA reactivity $[12,13]$. Therefore, it is likely that the size of CIC and/or inaccessibility of GalNAc to ASGP$\mathrm{R}$ due to the potential hindrance conferred by bound IgG prevent effective CIC clearance and increases their elimination through the kidneys [54]. Indeed, IgA-containing IC are present in the urine of IgAN patients in a signifi- cantly higher amount than in the urine of patients with other renal diseases with comparable proteinuria, and in healthy controls [54]. With disease progression, proteinuria increases and is often non-selective, so that high-molecular-weight proteins (such as immunoglobulins) cross the glomerular capillary wall and appear in the urine. These observations indicate that kidneys of IgAN patients are exposed to a high load of IgA1-containing CIC that are excreted in the urine by filtration across the damaged glomerular barrier. Indeed, their urinary levels positively correlated with proteinuria $(\mathrm{p}<0.001)$. These IC have a molecular mass of $650-850 \mathrm{kDa}$.

To evaluate the biological activity of various forms of IgA1- and IgG-containing IC, we developed a model with cultured human mesangial cells. First, we assessed binding of IgA1, Gal-deficient IgA1, and IgA1-containing CIC to these cells. Gal-deficient IgA1 bound better than did normally glycosylated IgA1. IgA1-containing IC from patients with IgAN bound with higher affinity to mesangial cells than did uncomplexed IgA1 [29]. This binding was mediated by a receptor different from CD89, ASGP-R, and the polymeric immunoglobulin receptor $[29,55,56]$.

To study the activation of cultured human mesangial cells by IgA1 and IgA1-containing IC, we measured changes in cellular proliferation. We used IgA1 IC from sera of IgAN patients and healthy controls purified by size-exclusion chromatography [29]. The incubation of mesangial cells with serum fractions with $M_{r} 800-900$ $\mathrm{kDa}$, rich with Gal-deficient IgA1, stimulated proliferation, while fractions with smaller complexes were inhibitory $[29,53]$. Furthermore, CIC containing larger molecular mass fractions isolated from serum of an IgAN patient collected during an episode of macroscopic hematuria stimulated proliferation of mesangial cells more than did CIC obtained during a subsequent quiescent phase. To examine the role of IgA, we removed IgA1 from the serum before fractionation. The resultant IgA1-depleted fractions were devoid of stimulatory IgA1-CIC. Sera of IgAN patients were also fractionated after addition of desialylated Gal-deficient pIgA1 to form additional IC. Supplementation with a small quantity of this IgA1 increased cellular proliferation in assays using serum fractions of $M_{r} \geq 800-900 \mathrm{kDa}$; uncomplexed IgA1 did not significantly affect MC proliferation [53]. In contrast, supplementation with a larger quantity of this IgA1 inhibited cellular proliferation in assays using serum fractions of $\mathrm{M}_{\mathrm{r}} 700-800 \mathrm{kDa}$. In summary, these findings suggest that CIC containing aberrantly glycosylated IgA1 affect proliferation of mesangial cells in vitro and thus likely play a role in the pathogenesis of IgAN. 
Table 1. Glycan deficiencies in patients with various diseases [summarized from refs. 9, 10, 16, 33, 52-58, 60-65]

\begin{tabular}{|c|c|c|}
\hline Disease & Afflicted molecules or cells & Deficiency \\
\hline IgA nephropathy & HR IgA1 & Gal in O-linked glycans \\
\hline Tn syndrome & $\begin{array}{l}\text { erythrocytes, lymphocytes, } \\
\text { monocytes, platelets, granulocytes }\end{array}$ & $\begin{array}{l}\text { Gal in } O \text {-linked glycans } \\
\text { - exposed Tn antigen }\end{array}$ \\
\hline Sjögren syndrome & $\operatorname{IgG}, \operatorname{IgA} 1, \operatorname{IgA} 2$ & Gal in $N$ - and/or $O$-linked \\
\hline $\begin{array}{l}\text { Rheumatoid arthritis } \\
\text { Juvenile onset rheumatoid arthritis } \\
\text { Systemic lupus erythematosus } \\
\text { Crohn's disease } \\
\text { Ulcerative colitis } \\
\text { Periodontal disease } \\
\text { Tuberculosis } \\
\text { Human immunodeficiency virus infection }\end{array}$ & $\operatorname{IgG}$ & $\begin{array}{l}\text { Gal in } N \text {-linked } \\
(\beta 1,4) \text { chains, exposed } \\
\text { GlcNAc }\end{array}$ \\
\hline Wiscott-Aldrich syndrome & B, T lymphocytes, platelets & GlcNAc in $O$-linked chains \\
\hline $\begin{array}{l}\text { Paroxysmal nocturnal } \\
\text { hemoglobinuria }\end{array}$ & $\begin{array}{l}\text { glycosylphosphatidylinositol on } \\
\text { erythrocytes, T cells, granulocytes }\end{array}$ & GlcNAc \\
\hline
\end{tabular}

\section{IgAN and Gal Deficiency in Other Diseases}

A growing body of evidence indicates that glycan moieties on free or cell-bound glycoproteins play essential roles in many biological processes and functions and that their alterations are demonstrable in a number of human diseases [57-61]. Interestingly, such aberrancies are most frequently manifested by a deficiency of Gal on $\mathrm{N}$ - and/or $O$-linked glycans (table 1). In diseases associated with chronic inflammation such as rheumatoid arthritis, systemic lupus erythematosus, juvenile onset rheumatoid arthritis, Sjögren syndrome, inflammatory bowel diseases, periodontal disease, tuberculosis, and infection with the human immunodeficiency virus [61-65], IgG molecules display Gal deficiency on $N$-linked glycans of IgG molecules. This Gal deficiency, that appears to be associated with altered activity of $\beta 1,4 \mathrm{Gal}$ transferase, results in the exposure of $\mathrm{N}$-acetylglucosamine (GlcNAc), which, in turn, leads to the potent activation of complement by the lectin pathway with all its inflammatory consequences $[64,65]$. This process ensues because the mannanbinding lectin also interacts with GlcNAc [65].

A rare disease, Tn syndrome, also termed mixed field polyagglutination, is characterized by the deficiency of $\mathrm{Gal}$ on $\mathrm{O}$-linked glycans on a broad spectrum or a single type of blood elements including erythrocytes, lymphocytes, monocytes, granulocytes, and/or platelets [66-69].
Molecular studies of involved cell populations revealed a Gal deficiency on cell-surface glycoproteins resulting in the exposure of Tn antigen that consists of three vicinary GalNAc residues [66]. The Tn epitope is recognized by naturally occurring, complement-activating ubiquitous IgM antibodies induced by commensal Gram-negative bacteria. As a result of such an interaction, agglutination of afflicted blood elements and their consequential lysis induce anemia and thrombocytopenia. Importantly, such clinical manifestations become apparent only in a very small proportion of such individuals. This is due to the finding that the percentage of Gal-deficient blood elements must be greater than 10\%; otherwise, the clinical symptoms of Tn syndrome do not develop. Despite the structural differences in the epitopes of Tn antigen on blood elements and the HR of IgA1, as well as the isotypes of corresponding anti-GalNAc antibodies, both diseases display similarities in their structural basis and pathogenetic mechanisms. It is apparent that in patients with IgAN the proportion of Gal-deficient versus normally glycosylated IgA1 and the level and isotype of GalNAcspecific antibodies resulting in the formation of nephritogenic CIC play a decisive role in the manifestation and severity of the disease.

Extensive evaluations of sera from IgAN patients and controls with respect to the reactivity with GalNAc-specific lectins clearly demonstrated distinct patterns with 
Fig. 3. A model of pathogenesis of IgAN. A portion of IgA1 molecules produced by plasma cells in patients with IgAN is Gal-deficient and is recognized by anti-glycan IgG (or IgA1) antibodies [12, 13, 38, 72]. The formed IC due to their size cannot enter the space of Disse to reach the asialoglycoprotein receptor (ASGP-R) on hepatocytes, but are able to pass through the larger fenestrae in glomerular capillaries overlying the mesangium. These deposited complexes induce glomerular injury and alter the urinary proteome.

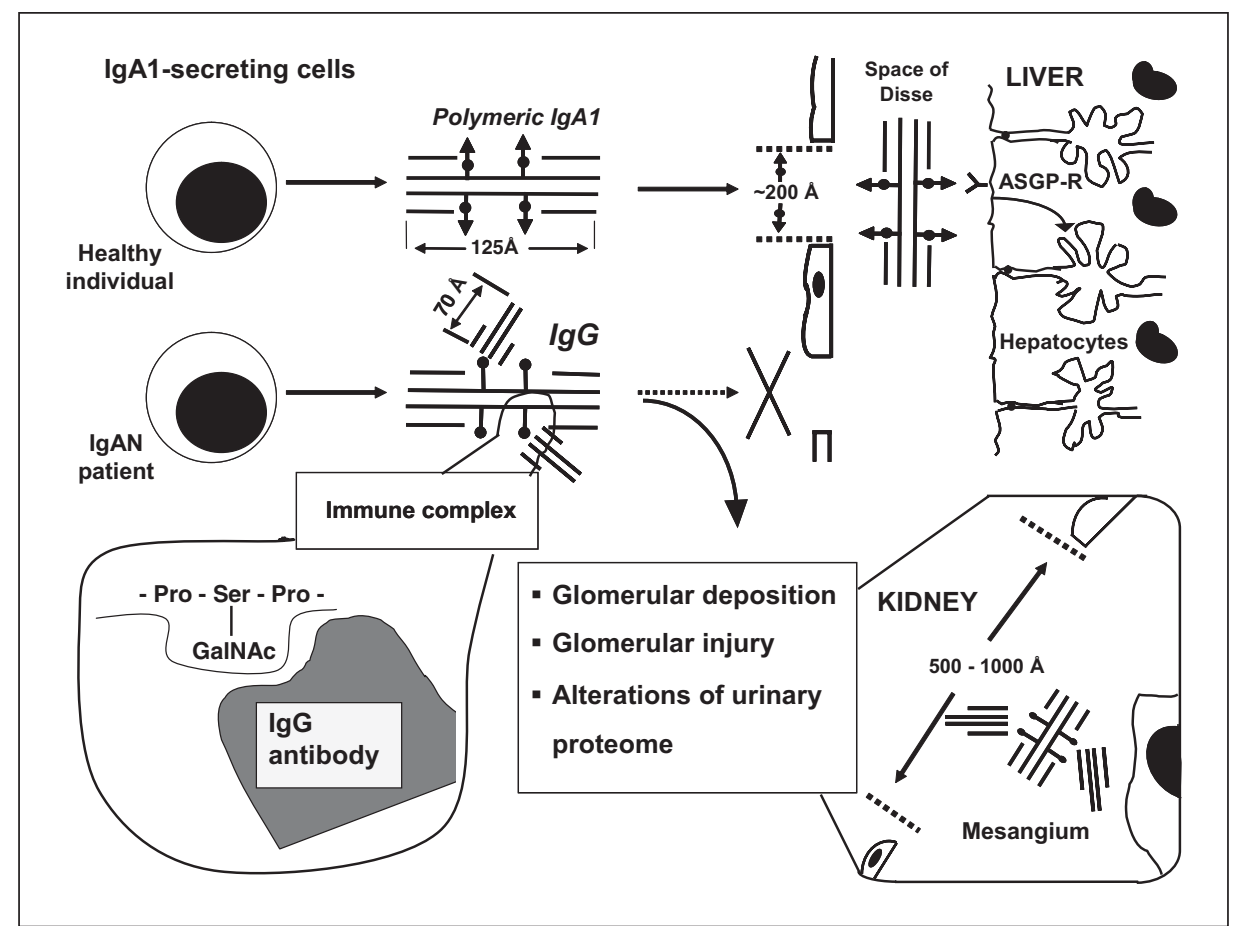

markedly higher Gal deficiency in the former population $[13,37,70]$. However, the lectin displayed remarkably varied binding, probably associated with the current stage of the disease. Although present at statistically significantly lower levels, binding to the lectin probe was also observed using sera from the control population, suggesting that a very small proportion of IgA molecules in apparently healthy individuals may also be Gal-deficient. Again, this finding stresses the importance of the proportion of the antigen (Gal-deficient IgA1) and antibodies in the generation of high-molecular-mass nephritogenic IgA1 CIC.

\section{Conclusion}

Identification of Gal-deficient IgA1 as an antigen and of GalNAc-specific IgG and/or IgA1 as an antibody involved in the formation of nephritogenic IC has potentially important implications for the pathogenesis of IgAN (fig. 3), and ultimately its treatment. As a consequence of infection, a portion of IgA1 molecules produced by plasma cells display a deficiency of Gal on $O$-linked glycans leading to the un-masking of novel GalNAc-associated epitopes. These epitopes react with corresponding naturally occurring antibodies and, depending on the antigen (pIgAl) to antibody proportions, form CIC of variable molecular masses. Large CIC cannot enter through endothelial fenestrae overlying the space of Disse to interact with hepatic ASGP-R. However, due to significantly larger endothelial fenestrae in glomerular capillaries, such CIC reach the mesangium and stimulate mesangial cells. A compilation and interpretation of these experimental results may provide an impetus for a rational new approach to the potential therapeutic intervention. Prevention of the formation of large nephritogenic CIC by monoclonal, small-molecular-weight, monovalent Fv fragments of antibodies with specificity and high affinity for the HR GalNAc epitopes may be one promising approach.

\section{Acknowledgments}

We thank Rose Kulhavy, Huong L. Vu, Rhubell Brown, Stacy Hall, Wen-Qiang Huang, Claretha R. Nichols, Candace Kirksey, Nagaraju Sarabu, Sandeep Anreddy, Lokesh Thakkalapati, and Cristy Salazar for their technical expertise, and Catherine V. Barker and Susan Y. Woodford for collection of the clinical samples. This work was supported by grants DK78244, DK61525, and DK71802 from the NIH and by General Clinical Research Center of the University of Alabama at Birmingham (M01 RR00032) (USA), and Research projects MSMT-0021620819, MSM0021620812, and KJ-586206106 (Czech Republic). 


\section{References}

1 Berger J, Hinglais N: Les dépôts intercapillaires d'IgA-IgG (intercapillary deposits of IgA-IgG). J Urol Nephrol 1968;74:694-695.

2 Barratt J, Feehally J: IgA Nephropathy. J Am Soc Nephrol 2005; 16:2088-2097.

-3 Coppo R, Amore A: Aberrant glycosylation in IgA nephropathy (IgAN). Kidney Int 2004;65:1544-1547.

4 Smith AC, Feehally J: New insights into the pathogenesis of IgA nephropathy: pathogenesis of IgA nephropathy. Springer Semin Immunopathol 2003;24:477-493.

5 Mestecky J, Russell MW: IgA subclasses. Monogr Allergy 1986;19:277-301.

-6 Mestecky J, Lue C, Tarkowski A, Ladjeva I, Peterman J, Moldoveanu Z, Russell MW, Brown TA, Radl J, Haaijman JJ, Kiyono H, McGhee JR: Comparative studies of the biological properties of human IgA subclasses. Protides Biol Fluids 1989;36:173-182.

7 Mestecky J, Moro I, Kerr MA, Woof JM: Mucosal immunoglobulins; in Mestecky J, Bienenstock J, Lamm ME, Mayer L, McGhee JR, Strober W (eds): Mucosal Immunology, ed 3. Amsterdam, Elsevier/Academic Press, 2005, pp 153-181.

$\checkmark 8$ Conley ME, Cooper MD, Michael AF: Selective deposition of immunoglobulin A1 in immunoglobulin A nephropathy, anaphylactoid purpura nephritis, and systemic lupus erythematosus. J Clin Invest 1980;66: 1432-1436.

-9 Russell MW, Mestecky J, Julian BA, Galla JH: IgA-associated renal diseases: antibodies to environmental antigens in sera and deposition of immunoglobulins and antigens in glomeruli. J Clin Immunol 1986;6:74-86.

$\checkmark 10$ Lai KN, Chan KW, Mac-Moune F, Ho CP, Yan KW, Lam CW, Vallance-Owen J: The immunochemical characterization of the light chains in the mesangial IgA deposits in IgA nephropathy. Am J Clin Pathol 1986;85: 548-551.

-11 Czerkinsky C, Koopman WJ, Jackson S, Collins JE, Crago SS, Schrohenloher RE, Julian BA, Galla JH, Mestecky J: Circulating immune complexes and immunoglobulin $\mathrm{A}$ rheumatoid factor in patients with mesangial immunoglobulin A nephropathies. J Clin Invest 1986;77:1931-1938.

-12 Tomana M, Matousovic K, Julian BA, Radl J, Konecny K, Mestecky J: Galactose-deficient IgA1 in sera of IgA nephropathy patients is present in complexes with IgG. Kidney Int 1997;52:509-516.

13 Tomana M, Novak J, Julian BA, Matousovic K, Konecny K, Mestecky J: Circulating immune complexes in IgA nephropathy consist of IgA1 with galactose-deficient hinge region and antiglycan antibodies. J Clin Invest 1999;104:73-81.
14 Emancipator SN, Gallo GR, Lamm ME: Experimental IgA nephropathy induced by oral immunization. J Exp Med 1983;157:572582.

15 Mestecky J, Waldo FB, Britt WJ, Julian BA, Tomana M, van den Wall Bake AWL, Russell MW, Galla JH, Moldoveanu Z, Jackson S: Exogenous antigens deposited in the glomeruli of patients with $\operatorname{IgA}$ nephropathy; in Sakai $\mathrm{H}$, Sakai O, Nomoto Y (eds): Pathogenesis of IgA Nephropathy. Tokyo, Harcourt Brace Jovanovich, 1990, pp 247-257.

-16 Ballardie FW, Brenchley PE, Williams S, O’Donoghue DJ: Autoimmunity in IgA nephropathy. Lancet 1988;ii:588-592.

17 van den Wall Bake AWL, Kirk KA, Gay RE, Switalski LM, Julian BA, Jackson S, Gay S, Mestecky J: Binding of serum immunoglobulins to collagens in IgA nephropathy and HIV infection. Kidney Int 1992;42:374-382.

18 André PM, Le Pogamp P, Chevet D: Impairment of jacalin binding to serum IgA in IgA nephropathy. J Clin Lab Anal 1990;4:115119.

19 MesteckyJ, Tomana M, Crowley-Nowick PA, Moldoveanu Z, Julian BA, Jackson S: Defective galactosylation and clearance of IgA1 molecules as a possible etiopathogenic factor in IgA nephropathy. Contrib Nephrol. Basel, Karger, 1993, vol 104, pp 172-182.

20 Allen AC, Bailey EM, Brenchley PEC, Buck KS, Barratt J, and Feehally J: Mesangial IgA1 in IgA nephropathy exhibits aberrant $O$-glycosylation: observations in three patients. Kidney Int 2001;60:969-973.

21 Hiki Y, Odani H, Takahashi M, Yasuda Y, Nishimoto A, Iwase H, Shinzato T, Kobayashi Y, Maeda K: Mass spectrometry proves under-O-glycosylation of glomerular IgA1 in IgA nephropathy. Kidney Int 2001;59: 1077-1085.

22 Mestecky J, Hashim OH, Tomana M: Alterations in the IgA carbohydrate chains influence the cellular distribution of IgA1. Contrib Nephrol. Basel, Karger, 1995, vol 111, pp 66-72.

23 Conley ME, Delacroix DL: Intravascular and mucosal immunoglobulin A: two separate but related systems of immune defense? Ann Intern Med 1987;106:892-899.

24 Mestecky J, Russell MW, Jackson S, Brown TA: The human IgA system: a reassessment. Clin Immunol Immunopathol 1986;40:105114.

25 Stockert RJ, Kressner MS, Collins JC, Sternlieb I, Morell AG: IgA interaction with the asialoglycoprotein receptor. Proc Natl Acad Sci USA 1982;79:6229-6231.

26 Mestecky J, Moldoveanu Z, Tomana M, Epps JM, Thorpe SR, Phillips JO, Kulhavy R: The role of the liver in catabolism of mouse and human IgA. Immunol Invest 1989;18:313324.
27 Moldoveanu Z, Moro I, Radl J, Thorpe SR, Komiyama K, Mestecky J: Site of catabolism of autologous and heterologous IgA in nonhuman primates. Scand J Immunol 1990;32: 577-583.

28 Tomana M, Kulhavy R, Mestecky J: Receptor-mediated binding and uptake of immunoglobulin A by human liver. Gastroenterology 1988;94:762-770.

29 Novak J, Vu HL, Novak L, Julian BA, Mestecky J, Tomana M: Interactions of human mesangial cells with IgA and IgA-containing immune complexes. Kidney Int 2002;62: 465-475.

30 Sumiyama K, Saitou N, Ueda S: Adaptive evolution of the IgA hinge region in primates. Mol Biol Evol 2002;19:1093-1099.

31 Kilian M, Russell MW: Microbial evasion of IgA functions; in Mestecky J, Bienenstock J, Lamm ME, Mayer L, McGhee JR, Strober W (eds): Mucosal Immunology, ed 3. Amsterdam, Elsevier/Academic Press, 2005, pp 291303.

- 32 Novak J, Tomana M, Kilian M, Coward L, Kulhavy R, Barnes S, Mestecky J: Heterogeneity of $O$-glycosylation in the hinge region of human IgA1. Mol Immunol 2000;37: 1047-1056.

33 Renfrow MB, Cooper HJ, Tomana M, Kulhavy R, Hiki Y, Toma K, Emmett MR, Mestecky J, Marshall AG, Novak J: Determination of aberrant $O$-glycosylation in the IgA1 hinge region by electron capture dissociation Fourier transform-ion cyclotron resonance mass spectrometry. J Biol Chem 2005; 280:19136-19145.

34 Renfrow MB, Mackay CL, Chalmers MJ, Julian BA, Mestecky J, Kilian M, Poulsen K, Emmett MR, Marxhall AG, Novak J: Analysis of $O$-glycan heterogeneity in IgA 1 myeloma proteins by Fourier transform ion cyclotron resonance mass spectrometry: implications for IgA nephropathy. Anal Bioanal Chem 2007;389:1397-1407.

35 Novak J, Moldoveanu Z, Renfrow MB, Yanagihara T, Suzuki H, Raska M, Hall S, Brown R, Huang W-Q, Goepfert A, Kilian M, Poulsen K, Tomana M, Wyatt RJ, Julian BA, Mestecky J: IgA nephropathy and Henoch-Schoenlein purpura nephritis: aberrant glycosylation of IgA1, formation of IgA1-containing immune complexes, and activation of mesangial cells. Contrib Nephrol. Basel, Karger, 2007, vol 157, pp 134-138.

36 Mestecky J, Suzuki H, Yanagihara T, Moldoveanu Z, Tomana M, Matousovic K, Julian BA, Novak J: IgA nephropathy: current views of immune complex formation. Contrib Nephrol. Basel, Karger, 2007, vol 157, pp 56-63. 
>37 Moore JS, Kulhavy R, Tomana M, Moldoveanu Z, Suzuki H, Brown R, Hall S, Kilian M, Poulsen K, Mestecky J, Julian BA, Novak J: Reactivities of $\mathrm{N}$-acetylgalactosamine-specific lectins with human IgA1 proteins. Mol Immunol 2007;44:2598-2604.

38 Suzuki H, Moldoveanu Z, Hall S, Brown R, Julian BA, Wyatt RJ, Tomana M, Tomino Y, Novak J, Mestecky J: IgA nephropathy: characterization of IgG antibodies specific for galactose-deficient IgA1. Contrib Nephrol. Karger, Basel, 2007, vol 157, pp 129-133.

-39 Barratt J, Feehally J, Smith AC: Pathogenesis of IgA nephropathy. Semin Nephrol 2004;24: 197-217.

-40 Novak J, Julian BA, Tomana M, Mestecky J: Progress in molecular and genetic studies of IgA nephropathy. J Clin Immunol 2001;21: 310-327.

-41 Jackson S: Immunoglobulin A-antiimmunoglobulin interactions and immune complexes in IgA nephropathy. Am J Kidney Dis 1988; $12: 425-429$

-42 Jackson S, Montgomery RI, Julian BA, Galla $\mathrm{JH}$, Czerkinsky C: Aberrant synthesis of antibodies directed at the Fab fragment of IgA in patients with IgA nephropathies. Clin Immunol Immunopathol 1987;45:208-213.

43 Jackson S, Montgomery RI, Mestecky J, Czerkinsky C: Normal human sera contain antibodies directed at Fab of IgA. J Immunol 1987; 138:2244-2248.

44 Jackson S, Montgomery RI, Mestecky J, Julian BA, Galla JH, Czerkinsky C: Antibodies directed at Fab of IgA in the sera of normal individuals and IgA nephropathy patients. Adv Exp Med Biol 1987;216B:1537-1544.

45 Iwasaki H, Zhang Y, Tachibana K, Gotoh M, Kikuchi N, Kwon YD, Togayachi A, Kudo T, Kubota T, Narimatsu H: Initiation of $\mathrm{O}$-glycan synthesis in IgA1 hinge region is determined by a single enzyme, UDP- $N$-acetyl- $\alpha$ D-galactosamine: polypeptide $\mathrm{N}$-acetylgalactosaminyltransferase 2. J Biol Chem 2003; 278:5613-5621.

-46 Ju T, Brewer K, D’Souza A, Cummings RD, Canfield WM: Cloning and expression of human core $1 \beta 1,3$-galactosyltransferase. J Biol Chem 2002;277:178-186.

-47 Ju T, Cummings RD: A unique molecular chaperone Cosmc required for activity of the mammalian core $1 \beta 3$-galactosyltransferase. Proc Natl Acad Sci USA 2002;99:1661316618.

-48 Ju T, Cummings RD: Protein glycosylation: chaperone mutation in Tn syndrome. Nature 2005;437:1252.
49 Kudo T, Iwai T, Kubota T, Iwasaki H, Takayma Y, Hiruma T, Inaba N, Zhang $Y$, Gotoh M, Togayachi A, Narimatsu H: Molecular cloning and characterization of a novel UDP-Gal:GalNAc $(\alpha)$ peptide $\beta$ 1,3-galactosyltransferase (C1Gal-T2), an enzyme synthesizing a core 1 structure of $O$-glycan. J Biol Chem 2002;277:47724-47731.

50 Raska M, Moldoveanu Z, Suzuki H, Brown R, Kulhavy R, Andrasi J, Hall S, Vu HL, Carlsson F, Lindahl G, Tomana M, Julian BA, Wyatt RJ, Mestecky J, Novak J: Identification and characterization of CMP-NeuAc: GalNAc-IgA1 $\quad \alpha 2,6$-sialyltransferase in IgA1-producing cells. J Mol Biol 2007;369: 69-78.

51 Schachter H, McGuire EJ, Roseman S: Sialic acids. 13. A uridine diphosphate D-galactose: mucin galactosyltransferase from porcine submaxillary gland. J Biol Chem 1971;246: 5321-5328.

52 Julian BA, Wyatt RJ, Matousovic K, Moldoveanu Z, Mestecky J, Novak J: IgA nephropathy: a clinical overview. Contrib Nephrol. Basel, Karger, 2007, vol 157, pp 19-26.

53 Novak J, Tomana M, Matousovic K, Brown R, Hall S, Novak L, Julian BA, Wyatt RJ, Mestecky J: IgA1-containing immune complexes in IgA nephropathy differentially affect proliferation of mesangial cells. Kidney Int 2005;67:504-513.

54 Matousovic K, Novak J, Yanagihara T, Tomana M, Moldoveanu Z, Kulhavy R, Julian BA, Konecny K, Mestecky J: IgA-containing immune complexes in the urine of IgA nephropathy patients. Nephrol Dial Transplant 2006;21:2478-2484

55 Leung JC, Tsang AW, Chan LY, Tang SC, Lam MF, Lai KN: Size-dependent binding of IgA to HepG2, U937, and human mesangial cells. J Lab Clin Med 2002;140:398-406.

56 Leung JC, Tsang AW, Chan DT, Lai KN: Absence of CD89, polymeric immunoglobulin receptor, and asialoglycoprotein receptor on human mesangial cells. J Am Soc Nephrol 2000;11:241-249.

57 Chui D, Sellakumar G, Green R, SuttonSmith M, McQuistan T, Marek K, Morris H, Dell A, Marth J: Genetic remodeling of protein glycosylation in vivo induces autoimmune disease. Proc Natl Acad Sci USA 2001; 98:1142-1147.

58 Dwek RA: Glycobiology: more functions for oligosaccharides. Science 1995;269:12341235.

59 Varki A: Biological roles of oligosaccharides: all of the theories are correct. Glycobiology 1993;3:97-130.

60 Nose M, Wigzell H: Biological significance of carbohydrate chains on monoclonal antibodies. Proc Natl Acad Sci USA 1983;80: 6632-6637.
61 Mestecky J, Tomana M: Structural heterogeneity of glycans in immunoglobulin molecules: Implications in IgA nephropathy. Nephrology 1997;3:S653-S657.

62 Moore JS, Wu X, Kulhavy R, Tomana M, Novak J, Moldoveanu Z, Brown R, Goepfert PA, Mestecky J: Increased levels of galactose-deficient IgG in sera of HIV-1-infected individuals. AIDS 2005;19:381-389.

63 Novak J, Tomana M, Shah GR, Brown R, Mestecky J: Heterogeneity of IgG glycosylation in adult periodontal disease. J Dent Res 2005;84:897-901.

64 Keusch J, Lydyard PM, Delves PJ: The effect on IgG glycosylation of altering $\beta 1,4$-galactosyltransferase- 1 activity in B cells. Glycobiology 1998;8:1215-1220.

65 Malhotra R, Wormald MR, Rudd PM, Fischer PB, Dwek RA, Sim RB: Glycosylation changes of IgG associated with rheumatoid arthritis can activate complement via the mannose-binding protein. Nat Med 1995;1: 237-243.

66 Berger EG: Tn-syndrome. Biochim Biophys Acta 1999; 1455:255-268.

67 Dahr W, Uhlenbruck G, Gunson HH, Van Der Hart M: Molecular basis of Tn-polyagglutinability. Vox Sang 1975;29:36-50.

68 Thurnher M, Rusconi S, Berger EG: Persistent repression of a functional allele can be responsible for galactosyltransferase deficiency in Tn syndrome. J Clin Invest 1993;91: 2103-2110.

69 Dausset J, Moullec J, Bernard J: Acquired hemolytic anemia with polyagglutinability of red blood cells due to a new factor present in normal human serum (Anti-Tn). Blood 1959; 14:1079-1093.

70 Moldoveanu Z, Wyatt RJ, Lee JY, Tomana M, Julian BA, Mestecky J, Huang WQ, Anreddy SR, Hall S, Hastings MC, Lau KK, Cook WJ, Novak J: Patients with IgA nephropathy have increased serum galactose-deficient $\operatorname{IgA} 1$ levels. Kidney Int 2007;71:1148-1154.

71 Mattu TS, Pleass RJ, Willis AC, Kilian M, Wormald MR, Lellouch AC, Rudd PM, Woof JM, Dwek RA: The glycosylation and structure of human serum IgA1, Fab, and Fc regions and the role of $N$-glycosylation on $\mathrm{Fc} \alpha$ receptor interactions. J Biol Chem 1998;273: 2260-2272.

72 Mestecky J, Novak J, Julian BA, Tomana M: Pathogenic potential of galactose-deficient IgA1 in IgA nephropathy. Nephrology 2002; 7:S92-S99. 